J Adolesc Health. 2013 February ; 52(2): . doi:10.1016/j.jadohealth.2012.06.013.

\title{
Parental Acceptability of Contraceptive Methods Offered to their Teen During a Confidential Health Care Visit
}

\author{
Lauren B Hartman, MD, \\ University of California, San Francisco \\ Mary-Ann Shafer, MD, \\ University of California, San Francisco \\ Lance M Pollack, PhD, \\ University of California, San Francisco \\ Charles Wibbelsman, MD, \\ Kaiser Permanente, San Francisco
}

Fay Chang, BA, and

University of California, San Francisco

Kathleen P Tebb, PhD

University of California, San Francisco

\begin{abstract}
Purpose-To examine parental acceptability of contraceptive methods offered confidentially to their adolescent daughter.
\end{abstract}

Methods-A random sample of 261 parents/guardians with a daughter between 12-17 completed a telephone survey examining the relationship between parental acceptability of seven contraceptive methods with adolescents' likelihood to have sex, parenting beliefs, parents' sexual health as teens, sexually transmitted infection (STI) knowledge, and demographic factors.

Results-Acceptability was highest for oral contraceptive pills (59\%), and lowest for intrauterine device (IUD) (18\%). Parental acceptance of teens' autonomy was significantly associated with increased acceptability of all methods. Parental knowledge of STIs was poor and $51 \%$ found it acceptable for clinicians to provide their sexually active teen with condoms.

Conclusion-Conclusions: Parents were more accepting of OCPs and condoms, compared to IUDs and implants. Parental recognition of their teen's autonomy was associated with greater parental acceptability of clinicians providing their adolescent with contraceptives (regardless of the specific type of method being offered).

(C) 2012 Society for Adolescent Medicine. Published by Elsevier Inc. All rights reserved.

Corresponding author: Lauren B Hartman, MD, 3333 Calif. St, Laurel Heights LH245, University of California, San Francisco, San Francisco, CA. 94143 - 0503, Phone: 401-952-4517, hartmanlb@ peds.ucsf.edu.

A poster was presented at The International Society for Sexually Transmitted Diseases Research in Quebec Canada in July 2011, at The Society for Adolescent Health and Medicine in New Orleans, Louisiana in March 2012, as well as at the Pediatric Academic Society in Boston, Massachusetts in April 2012.

Publisher's Disclaimer: This is a PDF file of an unedited manuscript that has been accepted for publication. As a service to our customers we are providing this early version of the manuscript. The manuscript will undergo copyediting, typesetting, and review of the resulting proof before it is published in its final citable form. Please note that during the production process errors may be discovered which could affect the content, and all legal disclaimers that apply to the journal pertain. 


\section{Keywords}

Contraception; Confidentiality; Adolescents; Parents

Unintended pregnancies and sexually transmitted infections (STIs) remain high among adolescents. ${ }^{1,2}$ Despite the availability of effective, reversible, and longer lasting contraceptives, ${ }^{3}$ few adolescents use these recommended methods. ${ }^{2}$ Parents can potentially improve utilization, ${ }^{4}$ yet many are uncomfortable talking with their teens or have inaccurate contraceptive information. ${ }^{5}$ Improving clinician-parent partnerships may strengthen contraceptive adherence; however doing so is challenging, especially in the context of confidential adolescent health services. ${ }^{6-8}$ This study examines parental acceptability of different contraceptives and explores factors that influence their attitudes.

\section{Methods}

\section{Sample}

Between August-October 2010 a random sample of parent/caregivers with an adolescent (12-17 years) were recruited from two large, diverse Northern California clinic enrollment databases. Parent/caregiver was defined as the key adult responsible for the health and well being of the child.

\section{Procedures}

The clinic chief mailed each randomly selected parent a letter, in English and Spanish, explaining the study. Parents who did not want to be contacted were instructed to indicate this by returning a pre-addressed stamped return card. Potential participants were phoned two weeks after the initial mailing. Verbal consent was obtained. The computer-assisted telephone interview took 45 -minutes. Participants received a $\$ 15$ grocery gift card. This study received human subjects approval from all participating institutions.

\section{Measures}

Parents were asked, "if your teen's doctor found out your daughter was having sex, is it acceptable or unacceptable to you for the doctor to provide the following methods to your teen confidentially. Methods were oral contraceptive pill (OCP), condoms, injectable contraception, transdermal patch, implant, intrauterine device (IUD), emergency contraception (EC). Brief definitions of each method were provided. Parents rated their acceptability of each method with a 4-point Likert scale (very acceptable to very unacceptable). The primary predictive variable was parental report of the likelihood of their adolescent having sex in the next year. Parents were also asked about their past sexual behavior and birth control use as a teen. Parental knowledge of STIs was the number of correct answers on five multiple-choice questions. We used three parent attitudinal scales developed as part of a larger study (derived from factor analyses and evaluated for internally consistency with Cronbach's alphas >.80): (1) parental need to know about teen's health and behaviors (5 items), (2) recognition of their teen's autonomy ${ }^{9}$ ( 7 items) and (3) parental trust in doctor (11 items e.g. physician communication ability, caring, respectfulness, etc). Two other parenting factors: parent-teen communication and parental need for control were represented by individual items.

\section{Analysis}

Attitude scale scores were computed as the mean of the item scores. Bivariate associations between parental acceptability of contraceptives and all other measures (including demographic characteristics) were assessed with Chi-square (categorical correlates) and t- 
tests (continuous correlates). Logistic regressions assessed the multivariate relationship between acceptability of each method with correlates having significant bivariate associations. Using a backward elimination procedure, iterations continued until all variables in the model other than perceived likelihood of sex (unable to be removed because it was the primary variable), achieved $p<.10$ and the model achieved fit $(p>.20$ on the Hosmer-Lemeshow goodness-of-fit test).

\section{Results}

A total of 5601 randomly selected parents/caregivers were mailed letters; 202 indicated that they did not want to be contacted. Of the 5399 parents/caregivers who did not return a refusal card, 1491 were reached by phone. Of those reached by phone, 1397 were eligible for participation, and 490 completed interviews (35\% overall response rate). Of these, 261 were with parents of a female teen. Table 1 presents demographic characteristics.

Parental acceptability was highest for OCP (59\% acceptable) followed by condoms (51\%), injectable contraception (46\%), EC (45\%), transdermal patch (42\%), implant (32\%), and IUD $(18 \%)$. Acceptability of IUD and implant was significantly lower than all other methods ( $\mathrm{p}<.05)$. Acceptability of OCP was significantly higher than all other methods ( $\mathrm{p}<$. $05)$ except condoms which approached significance $(\mathrm{p}=.051)$.

Multivariate analyses (see Table 2) showed that parents who reported their adolescent likely to have sex in the next year, our primary predictive variable, were more likely to accept condoms and EC. Parental recognition of their teen's autonomy was the only variable associated with significantly higher acceptability scores for all contraceptive methods.

\section{Discussion}

A majority of parents (59\%) were accepting of OCPs being offered to their daughter; yet only half reported acceptability of condoms. Furthermore, the most effective contraceptive methods, implant and IUD ${ }^{3}$, were acceptable to only a small minority of parents. The strongest predictor of acceptability across all methods was parental recognition of their teen's autonomy.

We also found that parents who perceived their teens likely to have sex were more accepting of only condoms and EC despite our prediction that this variable would increase acceptance of all contraceptive methods. Possibly, parents may associate these methods with a single episode of sex rather than condoning an ongoing sexual relationship, which would require a more permanent contraceptive method. Conversely, lower EC acceptability was associated with greater religious service attendance. Perhaps this subset of parents hold the misconception that EC causes abortions, which is condemned by many religious belief systems. Consistent with prior research ${ }^{10}$, this study also found that parental trust in the clinician improved parental acceptability.

There are several study limitations. This was part of a larger survey of confidential health services and did not explore parental understanding of the contraceptive methods. In addition, the response rate of 35\% may limit the findings' generalizability. Finally, although this study did include male caregivers, there were insufficient numbers to explore the attitudes of fathers in greater depth.

Parents are an important and often overlooked partner in efforts to prevent adolescent pregnancy and STIs. This study begins to address this gap and provides information on factors that influence parental acceptability of contraceptives offered to their adolescents. More research is needed to improve our understanding of barriers and facilitators of sexual 
health communication between clinicians, parents, and adolescents. Beyond educating parents about STIs and contraceptive options, especially longer-acting methods, clinicians can help parents understand that adolescent autonomy is a normal part of development and confidential health services can support adolescents' transition to adulthood.

\section{Acknowledgments}

Funding for this study was provided by the National Institute of Child Health \& Human Development R01HD053408. Drs. Hartman and Shafer were also supported in part by the Leadership in Adolescent Health interdisciplinary training grant MC00003 from the Maternal and Child Health Bureau.

Acknowledgement of persons: Dr. Shannon Thyne at the University of California San Francisco was the instrumental in the involvement of the San Francisco General Hospital Clinic site in the study.

I have listed everyone who contributed significantly to the work in the Acknowledgements.

\section{References}

1. Forhan SE, Gottlieb SL, Sternberg MR, et al. Prevalence of sexually transmitted infections among female adolescents aged 14 to 19 in the United States. Pediatrics. 2009; 124(6):1505-1512. [PubMed: 19933728]

2. Centers for Disease Control and Prevention (CDC). Vital signs: teen pregnancy--United States, 1991-2009. MMWR Morb Mortal Wkly Rep. 2011; 60(13):414-420. [PubMed: 21471949]

3. ACOG Practice Bulletin No. 121: Long-acting reversible contraception: Implants and intrauterine devices. Obstet Gynecol. 2011; 118(1):184-196. [PubMed: 21691183]

4. Commendador KA. Parental influences on adolescent decision making and contraceptive use. Pediatr Nurs. 2010; 36(3):147-156. 170. [PubMed: 20687307]

5. Eisenberg ME, Bearinger LH, Sieving RE, Swain C, Resnick MD. Parents' beliefs about condoms and oral contraceptives: are they medically accurate? Perspect Sex Reprod Health. 2004; 36(2):50 57. [PubMed: 15136207]

6. Ford C, English A, Sigman G. Confidential Health Care for Adolescents: position paper for the society for adolescent medicine. The Journal of adolescent health : official publication of the Society for Adolescent Medicine. 2004; 35(2):160-167. [PubMed: 15298005]

7. Achieving quality health services for adolescents. Pediatrics. 2008; 121(6):1263-1270. [PubMed: 18519499]

8. Adolescent access to comprehensive, confidential reproductive health care. Am J Public Health. $1991 ; 81(2): 241$.

9. Zimmer-Gembeck, MJ.; Collins, WA. Autonomy development during adolescents. In: Adams, GR.; Berzonsky, M., editors. Blackwell Handbook of Adolescence. Oxford: Blackwell Publishers; 2003. p. $175-204$.

10. Tebb K, Shafer M, Chang F, Hernandez L, Otero-Sabogal R. Understanding Latino Parents' Attitudes Toward Confidential Health Services for Their Teens. Journal of Adolescent Health. 2011; 48(2):S47. 


\section{Implications and Contributions}

This study examines parental attitudes toward contraceptive methods provided to adolescents in the context of a confidential visit. It identifies factors that influence parental acceptability of contraceptive services that can inform interventions to improve parental knowledge and acceptance of confidential reproductive health services for teens. 


\section{Table 1}

Demographic Characteristics

\begin{tabular}{|c|c|c|c|}
\hline & & & Frequency $(\%)$ \\
\hline \multirow[t]{25}{*}{ Parent } & Age & $27-35$ & $59(22.6)$ \\
\hline & & $36-45$ & $101(38.7)$ \\
\hline & & $46-55$ & $76(29.1)$ \\
\hline & & $>56$ & $23(8.8)$ \\
\hline & Gender & Male & $35(13.4)$ \\
\hline & & Female & $226(86.5)$ \\
\hline & Marital Status & Married & $183(70.1)$ \\
\hline & & Other & $77(29.8)$ \\
\hline & Race/Ethnicity & Non Hispanic white & $59(22.6)$ \\
\hline & & Non Hispanic black & $41(15.7)$ \\
\hline & & Hispanic & $119(45.6)$ \\
\hline & & Non Hispanic Other & $42(16.0)$ \\
\hline & Language Spoken & English-only & $180(69.0)$ \\
\hline & & Other & $81(31.0)$ \\
\hline & Income & $\$ 40,000$ or less & $84(32.2)$ \\
\hline & & $\$ 40,001$ to $\$ 80,000$ & $71(27.2)$ \\
\hline & & Over $\$ 80,000$ & $93(35.6)$ \\
\hline & Insurance & Self pay & $6(2.3)$ \\
\hline & & Kaiser & $206(78.9)$ \\
\hline & & Private insurance & $2(0.8)$ \\
\hline & & Public insurance & $46(17.6)$ \\
\hline & Religious Attendance & Once a week + & $92(35.2)$ \\
\hline & & $1,2,3$ times a month & $44(16.8)$ \\
\hline & & $<$ once a month & $61(23.4)$ \\
\hline & & Never & $61(23.4)$ \\
\hline \multirow[t]{6}{*}{ Teen } & Age of Teen & 12 or 13 & $93(35.6)$ \\
\hline & & 14 or 15 & $100(38.3)$ \\
\hline & & 16 or 17 & $68(26.1)$ \\
\hline & Birth Order & Only child & $41(15.7)$ \\
\hline & & Oldest child & $74(28.4)$ \\
\hline & & Other & $145(55.5)$ \\
\hline
\end{tabular}




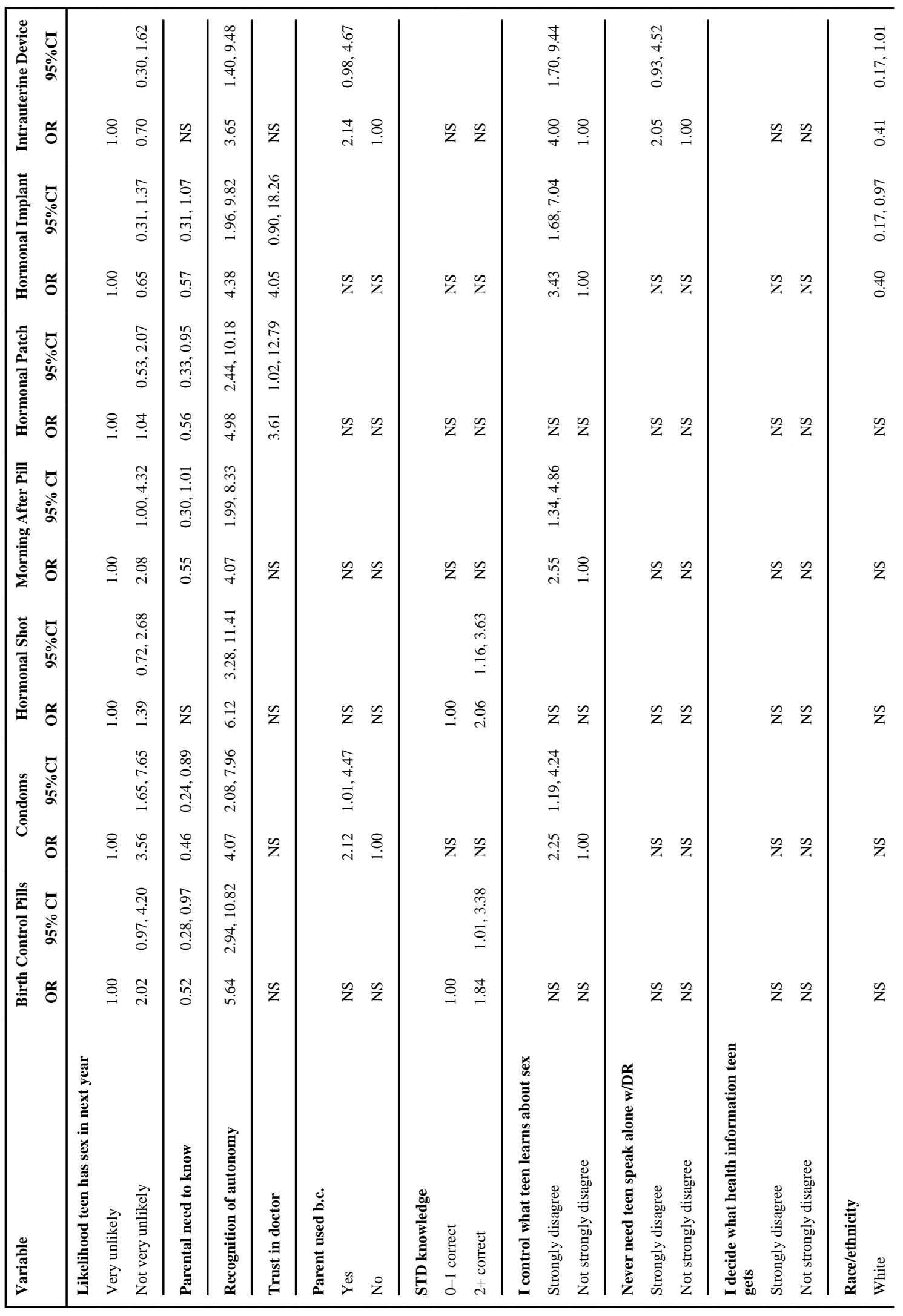




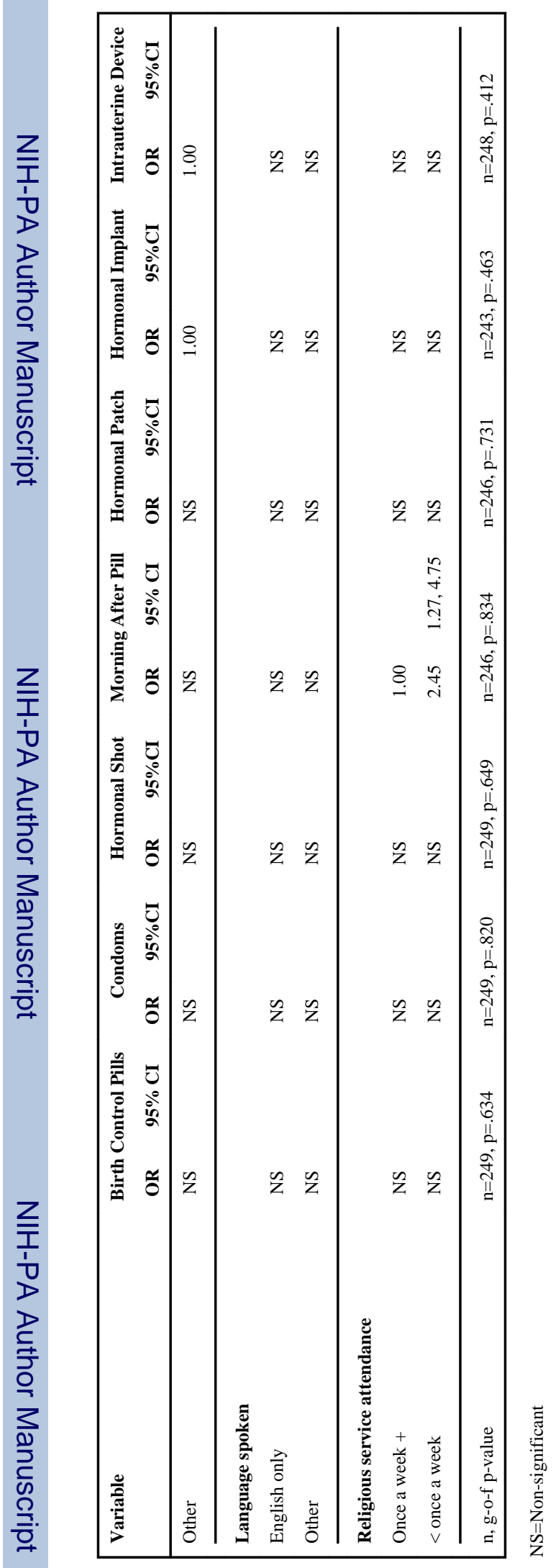

$J$ Adolesc Health. Author manuscript; available in PMC 2014 February 01. 